\title{
The changing tobacco epidemic
}

\author{
Adriana Blanco Marquizo
}

Secretariat of the WHO FCTC, an entity hosted by the World Health Organization, Geneve, GE, Switzerland

\section{Correspondence to}

Dr Adriana Blanco Marquizo, Secretariat of the WHO FCTC, an entity hosted by the World Health Organization, Geneve 1211, Switzerland: blancoa@who.int

Check for updates

(c) Author(s) (or their employer(s)) 2022. No commercial re-use. See rights and permissions. Published by BMJ.

To cite: Blanco Marquizo A. Tob Control

2022:31:173-174.
The latest archaeological discoveries suggest that humans in North America may have used tobacco some 12300 years ago-but probably completely differently from the use one sees nowadays. ${ }^{1}$ It was undoubtedly in the nineteenth century, with the creation of the Bonsack machine, when tobacco use as we know it, began and rapidly expanded. ${ }^{2}$

Around the 1940s and 1950s, the link between tobacco consumption and lung cancer was established, and by the end of the 1990s tobacco use was already the leading cause of premature death around the world. ${ }^{3}$

In 1993, confronted with the fact that the tobacco epidemic was global in nature and was clearly sustained by a transnational economic empire, a US lawyer, Dr Ruth Roemer, developed the idea of taking an international legal approach. Ten years later, that idea became the WHO Framework Convention on Tobacco Control (WHO FCTC), unanimously adopted by the Fifty-sixth World Health Assembly.

Today, the WHO FCTC has been in force close to 16 years, it boasts 182 Parties covering more than $90 \%$ of the world's population, and has developed a related protocol, the Protocol to Eliminate Illicit Trade in Tobacco products-a new independent treaty that entered in force in 2018.

But any treaty is only as strong as the enactment of its obligations at the country level. The overview of the tobacco control situation around the world, as seen in the articles published in this section, shows considerable disparity both in the implementation and enforcement of WHO FCTC-recommended measures.

According to data provided by the WHO FCTC Secretariat and WHO, both the number of Parties that have fully implemented at least some of the key demand reduction measures contained in the Convention and the percentage of the population thus protected by such complete measures, remain low: in the majority of the cases below $50 \%$. $^{45}$

Specific regional, subregional and domestic contexts make the implementation of tobacco control measures more difficult. The multiplicity of tobacco products-smoked and smokeless-in South Asia adds complexity to tobacco regulation in the region, especially when the main product consumed in the developed world is conventional cigarettes-which means that resources to help regulate other products, like bidis or waterpipes, are scarce. Also, the mix of big tobacco transnationals, small national producers and thousands of informal workers add to the challenges of tobacco regulation in those countries.
Other regions face complex humanitarian crises, as in many Eastern Mediterranean countries that are confronted with armed conflict and the resulting migrant populations. The small developing island states in Oceania and many of the countries in sub-Saharan Africa lack the resources to implement the entire array of regulatory measures on their own, and would benefit from regional or subregional approaches.

There are common barriers to the implementation of effective tobacco control measures. Lack of dedicated human and financial resources, lack of technical capacity, competing problems and lack of political will are cited across the globe. But the most persistent, pernicious and pervasive obstacle has been, and continues to be, interference by the tobacco industry and those who work to further its interests. If magically we could remove the tobacco industry from the equation, the other barriers would be much easier to solve.

This is how tobacco control has evolved to date, but if we want a different result in the future, a different approach is needed.

At the same time as the world is raising awareness regarding the negative impact of the commercial determinants of health and when the tobacco industry is known to be the epitome of that problem, this same industry is trying to gain-and sometimes succeeds at gaining - a seat at the policy discussion table.

There is no possibility of honest discussion with an industry whose interests are fundamentally irreconcilable with the interests of public health-an industry that profits from a product that kills up to half of its users.

There cannot be a sustainable future discussion over the dead bodies of the 100 million people killed by tobacco in the last century alone.

The industry now, as it has many times previously, is offering a 'solution' for the very problem it has created. But adding multiple addictive nicotine and tobacco products to the market without doing much more about the most lethal ones only complicates the work of ending the tobacco epidemic, and serves as a distraction.

The moment is now to ensure the full implementation of the core measures of the WHO FCTC, and its Protocol... and to go beyond. For many countries the possibility of an endgame strategy is in sight. The ways that countries reach that goal will be different according to the different circumstances prevailing in each of them. In the meantime, international cooperation and solidarity against the tobacco industry is the key to helping those countries that are 
lagging behind in making progress too, so that we can all achieve a healthy, tobacco-free future.

Twitter Adriana Blanco Marquizo @BlancoMarquizo

Funding The authors have not declared a specific grant for this research from any funding agency in the public, commercial or not-for-profit sectors.

Competing interests None declared.

Patient consent for publication Not applicable.

Ethics approval This study does not involve human participants.

Provenance and peer review Commissioned; externally peer reviewed.

Author note The author alone is responsible for the views expressed in this publication and he/she does not necessarily represent the views, decisions or policies of the secretariat of the WHO Framework Convention on Tobacco Control and the Protocol to Eliminate Illicit Trade in Tobacco products, nor the Governing Bodies of those treaties.
ORCID iD

Adriana Blanco Marquizo http://orcid.org/0000-0002-6665-6614

\section{REFERENCES}

1 Duke D, Wohlgemuth E, Adams KR, et al. Earliest evidence for human use of tobacco in the Pleistocene Americas. Nat Hum Behav 2021. doi:10.1038/s41562-021-01202-9. [Epub ahead of print: 11 Oct 2021].

2 Hilton MJ. The age of the cigarette. smoking, 2021. Available: https://www.britannica. com/topic/smoking-tobacco/The-age-of-the-cigarette\#ref845900

3 Proctor RN. The history of the discovery of the cigarette-lung cancer link: evidentiary traditions, corporate denial, global Toll. Tob Control 2012;21:87-91.

42021 global progress report on implementation of the who framework convention on tobacco control. Available: https://untobaccocontrol.org/downloads/fctc/who-fctc-gpr/ WHO-FCTC-Global-Progress-Report.pdf

5 WHO report on the global tobacco epidemic 2021: addressing new and emerging products. Available: https://www.who.int/teams/health-promotion/tobacco-control/ global-tobacco-report-2021 